\title{
PENGEMBANGAN MEDIA PEMBELAJARAN BERBASIS VIDEO ANIMASI SOFTWARE SOLIDWORKS 2014 DAN ADOBE FLASH CS3 PADA MATA PELAJARAN TEKNOLOGI DASAR OTOMOTIF (TDO) MATERI MOTOR BAKAR
}

\author{
I G. Adi Aryana1), L. J. E. Dewi'1), I N. Pasek Nugraha²) \\ Program Studi Pendidikan Teknik Mesin, Fakultas Teknik dan Kejuruan \\ Universitas Pendidikan Ganesha \\ Singaraja, Indonesia
}

e-mail: gede.adi.aryana@undiksha.ac.id, joni.erawatidewi@undiksha.ac.id, paseknugraha@undiksha.ac.id.

\begin{abstract}
Abstrak
Penelitian ini bertujuan untuk: 1) Mengetahui pengembangan media pembelajaran berbasis video animasi Software Solidworks 2014 dan Adobe Flash CS3, pada mata pelajaran Teknologi Dasar Otomotif (TDO) materi Motor Bakar. 2) Mengetahui kelayakan media pembelajaran berbasis video animasi Software Solidworks 2014 dan Adobe Flash CS3, pada mata pelajaran Teknologi Dasar Otomotif (TDO) materi Motor Bakar kelas X TBSM di SMK Negeri 3 Singaraja. Penelitian ini menggunakan jenis penelitian (R\&D) Research and Development, dengan model pengembangan 4D (Four $D$ models), yang terdiri dari 4 tahap yaitu tahap pendefinisian (define) tahap perancangan (design) tahap pengembangan (development) dan penyebaran (deseminate). Pada penelitian ini baru dilakukan 3 tahap, Hasil validitas dari 1) Ahli materi yaitu sangat layak dengan persentase $85.33 \%$, 2) Ahli media memberikan hasil dengan persentase sebesar $90 \%$ sehingga kriteria dari segi media sangat layak, 3) Uji coba kelompok kecil memperoleh persentase sebesar $86.5 \%$, sehingga dapat dinyatakan dalam kriteria sangat layak, 4) Uji coba kelompok besar mendapatkan kriteria sangat layak dengan persentase sebesar $89.2 \%$. Berdasarkan hasil pembahasan dari penelitian dan pengembangan ini dapat dinyatakan sangat layak dari segi materi, dan media serta tanggapan dari siswa, sehingga media ini dapat dinyatakan sangat layak digunakan untuk pembelajaran.
\end{abstract}

Kata Kunci: Media Pembelajaran, Video Animasi, Solidworks 2014, Adobe Flash CS3, Motor Bakar.

\footnotetext{
Abstract

This study aims to: 1) determine the development of instructional media Based on Animation Video of Software Solidworks 2014 And Adobe Flash CS3 in Eyes of Automotive Basic Technology (ABT) Theory of Combustion Engine. 2) determine the feasibility of learning media based On Animation Video of Software Solidworks 2014 And Adobe Flash CS3 in Eyes of Automotive Basic Technology (ABT) Theory of Combustion Engine for Class X TBSM in SMK Negeri 3 Singaraja. This study uses a type of research (R\&D) Research and Development, with a 4-D development model (Four D model), which consists of 4 stages, namely the stage of defining, the design phase of development and the development of deseminate). In this research, only 3 stages have been carried out. The results of the validity of 1) Theory experts are very decent with a percentage of $85.33 \%, 2$ ) Media experts give results with a percentage of $90 \%$ so that the criteria in terms of the media are very feasible, 3) Small group trials get a percentage of $86.5 \%$, so that it can be stated in very feasible criteria, 4) Large group trials get a very feasible criterion with a percentage of $89.2 \%$. Based on the results of the discussion of this research and development can be declared very feasible in terms of material, and the media and responses from students, so that this media can be declared very feasible to use for learning.
} 
Keywords: Learning Media, Animation Video, Solidworks 2014, Adobe Flash CS3, Combustion Engine.

\section{PENDAHULUAN}

yang telah dilakukan pada saat pelaksanaan PPL-Awal dan PPL-Real di SMK Negeri 3 Singaraja, menunjukan proses belajar mengajar pada mata pelajaran Teknologi Dasar Otomotif (TDO) materi motor bakar untuk kelas X TBSM terlihat sangat pasif, dimana siswa hanya sebagai penerima, pendengar dan pembaca sehingga terlihat siswa tidak bersemangat dalam pembelajaran, hal itu ditunjukkan dengan banyaknya siswa yang tidak memperhatikan penjelasan dari guru, disamping itu juga siswa jarang bertanya dan menjawab pertanyaan dari guru, sehingga tidak ada interaksi antara guru dan siswa, secara tidak langsung siswa kurang termotivasi dalam mengikuti pembelajaran. Dari hasil wawancara dengan guru pengampu mata pelajaran Teknologi Dasar Otomotif (TDO) untuk kelas X TBSM, menjelaskan bahwa banyak siswa yang remedi khususnya pada materi motor bakar yang dilihat dari hasil ulangan harian siswa dibawah Kriteria Ketuntasan Minimal (KKM) yaitu dibawah 75, yang dimana mata pelajaran Teknologi Dasar Otomotif (TDO) merupakan mata pelajaran yang menitik beratkan pada hasil belajar siswa yang bersifat kognitif, selain itu dari hasil wawancara dengan Kepala Bengkel (Kabeng) TBSM, yang memimpin jurusan TBSM di SMK Negeri 3 Singaraja, mengatakan bahwa pengembangan dan pembuatan media pembelajaran sangat dibutuhkan untuk membantu guru yang mengajar di TBSM, segala jenis media pembelajaran akan diterima apabila dapat membantu siswa dalam proses belajar mengajar dan siswa dapat cepat mengerti, sekaligus siswa termotivasi. Media pembelajaran berbasis video animasi merupakan suatu alat bantu yang dimana dapat menyajikan materi secara visual sehingga siswa lebih mudah memahami materi pada saat proses belajar mengajar berlangsung, media pembelajaran berbasis video animasi saat ini masih belum dimanfaatkan guru secara optimal dalam dunia pendidikan khususnya guru di jurusan TBSM SMK Negeri 3 Singaraja, oleh sebab itu seharusnya kita bisa membuat sebuah terobosan baru yaitu dengan menggunakan media pembelajaran berbasis video animasi yang secara visual dapat dilihat tanpa harus kita membawa mesin nyatanya ke dalam kelas karena media ini bisa membuat gambaran mesin secara spesifik dan proses kerjanya selain itu juga pembelajaran dengan video ataupun animasi menurut para ahli lebih berhasil dari pada dengan hanya menggunakan media jenis audio atau visual saja, karena disamping media ini lebih menarik, dampak yang dihasilkan juga akan lebih maksimal karena bisa masuk lewat dua sensor manusia yaitu mata dan telinga, dengan media ini pula, peserta didik akan merasa bahwa mereka seolah-olah terlibat di dalam kegiatan itu sendiri, sehingga motivasi dan minat belajar akan timbul lebih besar lagi, dengan kelebihan tersebut, diharapkan dapat menjawab masalah yang ada dan terwujud sebuah aplikasi media pembelajaran yang atraktif dan menarik bagi siswa khususnya siswa kelas $X$ TBSM yang cenderung masih dalam tahap awal mengikuti pembelajaran, secara tidak langsung mereka masih awam dengan mesin kendaraan apalagi mereka yang sedari awal tidak berminat di jurusan tersebut sehingga siswa tersebut merasa jenuh jika kita hanya menggunakan media pembelajaran yang konvensional, hanya teori, dan siswa diminta untuk berfikir abstrak, membayangkan bentuk dan sebagainya.

Yang dimaksud dengan media pembelajaran adalah "segala sesuatu yang dapat digunakan untuk menyampaikan pesan atau informasi dalam proses belajar mengajar sehingga dapat merangsang perhatian dan minat siswa dalam belajar" (Arsyad, 2013:10). Lebih lanjut Gagne dan Briggs (dalam Arsyad, 2013:4) secara eksplisit mengatakan bahwa media pembelajaran meliputi alat yang secara fisik digunakan untuk menyampaikan isi materi pengajaran. 
landasan teori penggunaan media dalam proses belajar disampaikan oleh Dale (dalam Arsyad, 2013:13) yaitu Dale's Cone of experience (Kerucut Pengalaman Dale) kerucut ini merupakan elaborasi yang rinci dari konsep tiga tingkatan pengalaman yang dikeluarkan oleh Burner. Dalam kerucut tersebut dijelaskan bahwa pengalaman secara langsung (kongkrit) memberikan hasil belajar paling tinggi, Dilanjutkan oleh benda tiruan, dramatisasi, karyawisata, televisi, gambar hidup pameran, gambar diam, lambang visual dan lambang kata (abstrak) yang memberikan porsi paling sedikit. (Sudjana dan Rivai, 2013:2) menyampaikan bahwa media pembelajaran dapat meningkatkan hasil belajar siswa, yaitu: 1) Pengajaran akan lebih menarik perhatian siswa sehingga dapat menumbuhkan motivasi belajar, 2) Bahan pelajaran akan lebih jelas maknanya sehingga dapat lebih dipahami oleh siswa, dan memungkinkan siswa menguasai tujuan pembelajaran lebih baik, 3) Metode mengajar akan lebih bervariasi, tidak semata-mata penuturan verbal melalui penuturan kata-kata oleh guru. Sehingga siswa tidak bosan, dan guru tidak kehabisan tenaga, apalagi bila guru mengajar untuk setiap jam pelajaran, 4) Siswa lebih banyak melakukan kegiatan belajar, sebab tidak hanya mendengarkan uraian guru, tetapi juga aktivitas lain seperti mengamati, melakukan, mendemonstrasikan, dan lain-lain. Animasi adalah "proses penciptaan efek gerak atau efek perubahan bentuk yang terjadi selama beberapa waktu (morphing)" (Salim, 2003:1). Suheri (2006:28) mengatakan bahwa animasi merupakan kumpulan gambar yang diolah sedemikian rupa sehingga menghasilkan gerakan.

Salah satu keunggulan animasi adalah kemampuannya untuk menjelaskan suatu kejadian secara sistematis dalam tiap waktu perubahan, hal ini sangat membantu dalam menjelaskan prosedur dan urutan kejadian.

\section{METODE}

Jenis penelitian yang dilakukan tergolong penelitian dan pengembangan atau disebut dengan (R\&D) Research and Development, yang dapat diartikan "sebagai suatu proses atau langkah-
Software Solidworks 2014 adalah sebuah software program rancang bangun yang banyak digunakan untuk mengerjakan desain produk, desain mesin, desain konstruksi, ataupun keperluan teknik yang lain (Sarwanto, 2013:2). Software solidworks dilengkapi dengan tool yang digunakan untuk membuat sebuah desain produk ataupun komponenkomponen dalam sebuah produk yang akan kita buat. Desain produk dalam bentuk 3D yang dibuat per part dari produk yang kita buat dan nantinya kita akan lakukan assembly untuk menyatukan komponen-komponen yang telah kita buat. Dengan software solidworks juga kita bisa membuatkan animasi dalam bentuk video rancangan desain produk yang akan kita buat.

Adobe Flash CS3 merupakan software yang mampu menghasilkan presentasi, game, film, CD interaktif, maupun CD pembelajaran, serta untuk membuat situs web yang interaktif, menarik, dan dinamis. Adobe Flash CS3 mampu melengkapi situs web dengan beberapa macam animasi, suara, animasi interaktif, dan lain-lain sehingga pengguna sambil mendengarkan penjelasan mereka dapat melihat gambar animasi, maupun membaca penjelasan dalam bentuk teks (Sutopo, 2003: 60).

Suharsimi (dalam Sudaryono dkk, 2013:30) instrumen pengumpulan data adalah alat bantu yang dipilih dan digunakan oleh peneliti dalam kegiatannya mengumpulkan agar kegiatan tersebut menjadi sistematis dan dipermudah olehnya. Tujuan penyebaran angket ialah mencari informasi yang lengkap mengenai suatu masalah dari responden tanpa merasa khawatir bila responden memberikan jawaban yang tidak sesuai dengan kenyataan dalam pengisian daftar pertanyaan atau pernyataan (Sudaryono, 2013:30-31).

langkah untuk mengembangkan suatu produk baru atau menyempurnakan produk yang telah ada, yang dimaksud produk dalam konteks ini adalah tidak selalu berbentuk hardware (Buku, Modul, Alat 
bantu di kelas, dll), namun bisa berupa perangkat lunak atau Software seperti program untuk mengolah data, pembelajaran di kelas, perpustakaan, atau model pendidikan, dIl" (Sukmadinata, 2010:164). Pengembangan media dengan metode (Research and Development) adalah "metode penelitian yang digunakan untuk menghasilkan produk tertentu, dan menguji keefektifan produk tersebut" (Sugiyono, 2012:407).

(Borg and Gall, 2003:624) menambahkan educational research and development is a process used to develop and validate educational product bisa diartikan bahwa penelitian pengembangan dalam hal ini di bidang pendidikan digunakan untuk mengembangkan dan memvalidasi produk-produk pendidikan. Sejalan dengan hal tersebut (Putra, 2012:88) menyebutkan bahwa pengembangan media research and development tepat digunakan untuk meneliti dengan inovasi untuk menemukan model, produk, prosedur, metode baru dan hendak mengukur efektivitas, produktivitas dan kualitasnya.

Metode penelitian yang digunakan dalam penelitian ini adalah rancangan penelitian model pengembangan perangkat pembelajaran yang disusun dalam penelitian ini mengacu pada jenis pengembangan 4-D (Four D model), yang terdiri dari 4 tahap yaitu tahap pendefinisian (define), tahap perancangan (design) tahap pengembangan (development) dan penyebaran (deseminate). Pada penelitian ini baru dilakukan 3 tahap, yaitu tahap pendefinisian (Define), tahap perancangan (Design), tahap pengembangan (Develop). Dalam penelitian ini, digunakan model 4-D (four-D model) yang dikemukakan oleh (Thiagarajan, 1974:6-8) karena dalam penelitian ini mengembangkan media pembelajaran berbasis video animasi Software Solidworks 2014 dan Adobe Flash CS3.

Dari model 4-D (Four $D$ model) adapun tahap yang dilakukan pada pengembangan media pembelajaran berbasis video animasi Software Solidworks 2014 dan Adobe Flash CS3, yaitu: Tahap Pendefinisian (Define) Tahap ini bertujuan menetapkan dan mendefinisikan kebutuhan-kebutuhan pembelajaran dengan menganalisis tujuan dan batasan materi. Ada 5 langkah dalam tahap ini yaitu: a) Analisis awal-akhir, pada tahap ini dilakukan analisis terhadap kurikulum yang berlaku di sekolah untuk menetapkan masalah dasar yang diperlukan dalam pengembangan perangkat pembelajaran serta dilakukan analisis pada teori belajar yang relevan, dan tuntutan belajar yang harus dicapai sehingga diperoleh deskripsi pola pembelajaran yang dianggap paling ideal. Setelah menemukan deskripsi pola pembelajaran yang relevan, kemudian dilakukan analisis pada materi motor bakar yang sesuai untuk dipadukan dengan media yang dikembangkan yaitu perangkat pembelajaran yang berbasis video Animasi Software Solidworks 2014 dan Adobe Flash CS3. b) Analisis Siswa, analisis siswa merupakan telaah tentang karakteristik siswa kelas X TBSM di SMK Negeri 3 Singaraja. Adapun karakteristik yang dianalisis meliputi: latar belakang pengetahuan, dan perkembangan kognitif siswa serta motivasi siswa dalam mengikuti pembelajaran di kelas. Hasil analisis siswa digunakan sebagai dasar analisis konsep dan tugas yang sesuai dengan rancangan dan pengembangan media pembelajaran berbasis video Animasi Software Solidworks 2014 dan Adobe Flash CS3. c) Analisis Konsep, aanalisis konsep diajukan untuk memilih, merinci dan menetapkan secara sistematis konsep yang relevan yang akan diajarkan berdasarkan analisis awal akhir. Analisis ini merupakan dasar dalam menyusun tujuan pembelajaran. d) Analisis Tugas, analisis tugas merupakan pengidentifikasian keterampilanketerampilan utama yang diperlukan dalam pembelajaran kemudian menganalisisnya ke dalam suatu kerangka sub-sub keterampilan yang lebih spesifik. e) Perumusan Indikator dan Tujuan Pembelajaran, tahap ini dilakukan untuk merumuskan hasil analisis konsep dan analisis tugas yang sebelumnya telah dilakukan. Tahap Perancangan (Design) Pada tahap ini dilakukan perancangan perangkat pembelajaran yang akan dikembangkan yaitu media pembelajaran 
berbasis video animasi Software Solidworks 2014 dan Adobe Flash CS3. Di dalam tahap ini dilakukan membuat: a) Membuat Outline Konten, pada langkah ini harus dirancang berdasarkan tujuan pembelajaran dan target utama, sehingga pada tampilan media terdapat judul yang sesuai dan penyajian isi sesuai dengan target yang ditentukan. b) Membuat Flowchart, hasil tahap ini berupa rancangan awal perangkat pembelajaran yang merupakan media awal beserta instrument penelitian. Produk yang dihasilkan berupa multimedia pembelajaran berbasis video animasi Software Solidworks 2014 dan Adobe Flash CS3. Media diawali dengan menu utama. Di menu utama, pengguna dapat melihat 5 (lima) pilihan yaitu: KI\&KD, materi, latihan, dan biodata. Ketika masuk materi, terdapat penjelasan materi, video cara kerja dan evaluasi. c) Pemilihan Media, Pemilihan media dilakukan untuk menentukan media yang tepat dalam penyajian materi pembelajaran yang bersumber dari media dengan landasan bahwa konsep dan prinsip sesuai standar kompetensi menerapkan dasar-dasar teknik digital dan animasi yang akan disampaikan melekat pada media tersebut. Proses pemilihan media disesuaikan dengan analisis tugas, analisis materi, karakteristik siswa dan fasilitas yang tersedia di sekolah. Pada pengembangan media pembelajaran berbasis video animasi ini menggunakan sofware Solidwork 2014 dan Adobe Flash CS3. d) Pemilihan Format Pada langkah ini rumusan format yang akan digunakan dalam mengembangkan perangkat pembelajaran serta mengkaji dan memilih media yang disesuaikan dengan kurikulum di SMK Negeri 3 Singaraja. Dalam penelitian ini media yang dihasilkan berupa media pembelajaran berbasis video animasi Software Solidworks 2014 dan Adobe Flash CS3, berupa perangkat lunak atau Software yang berformat (.exe) dan disajikan dalam bentuk Compact Disc (CD).

Tahap Pengembangan (Develop) Tujuan dari tahap pengembangan adalah untuk mengembangkan media dengan memproduksi komponen pada media seperti teks, gambar, auido, dan video, kemudian menggabungkannya agar menjadi bagian-bagian yang terintegrasi dan menghasilkan media final perangkat pembelajaran yang telah direvisi berdasarkan masukan para ahli dan data yang diperoleh dari uji coba. Kegiatan pada tahap ini adalah penilaian para ahli dan uji coba lapangan. a) Penilaian Para Ahli Rancangan media pembelajaran berbasis video animasi Software Solidworks 2014 dan Adobe Flash CS3 yang telah disusun pada tahap perancangan (media I), akan dilakukan penilaian/di validasi oleh para ahli (validator). Para validator tersebut adalah mereka yang berkompeten dan mengerti tentang penyusunan media pembelajaran berbasis video animasi Software Solidworks 2014 dan Adobe Flash CS3 dan mampu memberi masukan atau saran untuk menyempurnakan media pembelajaran yang telah disusun. Adapun hal-hal yang di validasi oleh validator mencakup:

1) Validasi isi Instrumen, dalam validitas isi berbagai cara yang dapat digunakan yang tujuannya adalah untuk melihat kesepakatan dari 2 pakar atau lebih dalam menilai keseluruhan konten. Menurut (Gregory, 2000) validitas isi menunjukan sejauh mana pertanyaan, tugas atau butir dalam suatu tes atau instrumen mampu mewakili secara keseluruhan dan proporsional perilaku sampel yang dikenai perlakuan tersebut. Artinya instrumen yang ada mencerminkan keseluruhan konten atau materi yang diujikan atau yang seharusnya dikuasai secara proporsional. Adapun rumus yang digunakan untuk analisis validasi isi oleh 2 pakar/ahli adalah rumus Gregory (kolom D dibagi dengan $A+B+C+D$ ), berikut merupakan tabel tabulasi silang gregory 2x2:

Tabel 01 Tabulasi silang 2x2 Gregory

\begin{tabular}{|c|c|c|c|}
\hline & \multicolumn{2}{|c|}{ Penguji I } \\
\hline & & $\begin{array}{c}\text { Tidak } \\
\text { Relevan }\end{array}$ & Relevan \\
\hline \multirow{2}{*}{$\begin{array}{c}\text { Penguji } \\
2\end{array}$} & $\begin{array}{c}\text { Tidak } \\
\text { Relevan }\end{array}$ & (A) & (B) \\
\hline & Relevan & (C) & (D) \\
\hline
\end{tabular}

2) Validasi Materi, pada media pembelajaran berbasis video animasi 
Software Solidworks 2014 dan Adobe Flash CS3 bertujuan untuk mengetahui perangkat pembelajaran sesuai dengan materi pelajaran dan tujuan yang akan diukur, dibuat jelas dan menarik untuk pemakaiannya. Apakah ilustrasi perangkat pembelajaran (gambar, tabel, dan lain sebagainya) dapat memperjelas konsep dan mudah dipahami. Hasil dari validasi ahli isi tersebut akan dijadikan bahan untuk merevisi media I sehingga menghasilkan perangkat pembelajaran media II, yang kemudian disempurnakan menjadi perangkat final.

3) Validasi Media, pada media ini telah didesain untuk memenuhi persyaratan konstruksi dan deduktif. Persyaratan konstruksi tersebut meliputi syarat- syarat yang berkenaan dengan penggunaan bahasa, susunan kalimat, kosakata, tingkat kesukaran dan kejelasan yang pada hakekatnya haruslah tepat guna dalam arti dapat dimengerti oleh pihak pengguna media yaitu peserta didik. Sedangkan syarat deduktif artinya bahwa media tersebut haruslah memenuhi asasasas yang efektif. Saran-saran dari para ahli (validator) tersebut akan dijadikan bahan untuk merevisi desain media awal sehingga menghasilkan perangkat pembelajaran yang lebih baik. Hasil validasi tersebut akan dijadikan bahan untuk merevisi media II sehingga menghasilkan perangkat pembelajaran media III, yang kemudian disempurnakan menjadi perangkat final.

4) Menggunakan angket respon siswa sebagai sumber informasi yang dapat dipercaya, sehingga diperoleh data yang dapat mendukung penelitian. Angket diberikan untuk mengetahui tanggapan siswa terhadap media yang telah dihasilkan. Instrumen Pengumpulan Data. Instrument yang digunakan untuk memperoleh sejumlah data yang diharapkan akan digunakan sebagai instrument pengumpulan data yaitu berupa angket. Pengumpulan data yang digunakan ini dapat dijelaskan sebagai berikut: Angket yang digunakan untuk mengumpulkan data yang mengenai ketepatan komponen bahan ajar, ketepatan perancangan desain pembelajaran, ketepatan isi atau materi bahan ajar, ke menarikan dan keefektifan penggunaan media pembelajaran.

Penelitian dan pengembangan ini menggunakan teknik analisis data statistik deskriptif persentase dan jenis data yang digunakan adalah data kuantitatif. Statistik deskriptif merupakan "metode statistik yang digunakan untuk menganalisis data dengan cara mendeskripsikan atau menggambarkan data yang telah terkumpul sebagaimana adanya tanpa bermaksud membuat kesimpulan yang berlaku umum atau generalisasi" (Sugiyono, 2016:147), sedangkan analisis deskriptif persentase merupakan metode yang digunakan untuk mendeskripsikan masing-masing variabel, dikarenakan data dari angket dalam penelitian ini merupakan data kuantitatif maka akan dianalisis secara deskriptif persentase.

Terdapat dua rumus yang digunakan dalam menganalisis data kuantitatif yang telah didapat. Data yang telah terkumpul dari uji coba produk selanjutnya diolah agar mendapat rata-rata dengan membuat persentase dengan rumus analisis per item soal dan keseluruhan. Adapun rumus yang digunakan untuk pengolahan data yaitu sebagai berikut:

Rumus untuk Rata-rata per item soal (Purwanto, 2012:101) :

$\mathrm{P}=\quad F$

Keterangan:

$\mathrm{F}=$ jumlah presentase keseluruhan subjek

$\mathrm{N}$ = Banyak Subjek

$\mathrm{P}=$ Persentase

Rumus untuk rata-rata keseluruhan (Purwanto, 2012:101):

$\mathrm{P}=\frac{\left.\sum \text { (Nilai Angket }\right)}{n \times \text { Bobot Terting } i} \times 100$

Keterangan:

$\mathrm{P} \quad=$ Persentase

$\Sigma \quad=$ Jumlah

$\mathrm{n} \quad=$ jumlah seluruh item angket

Sedangkan untuk penentuan kriteria kualifikasi tingkat kelayakan penilaian berdasarkan persentase dengan cara sebagai berikut: 1) Menentukan persentase skor maksimal $=100 \%$. 2) Menentukan persentase skor minimal $=20 \%$. 3) Menentukan lebar interval $=100-20=80$. 
4) Menentukan kelas interval, yaitu 5 (sangat layak, layak, cukup layak, kurang layak, tidak menarik). 5) Menentukan lebar rentangan interval: 80:5=16 Berdasarkan perhitungan dan cara di atas maka tabel distribusi range persentase dan kriteria kualitatif dapat ditetapkan seperti pada tabel 02

Jadi untuk mendapatkan media yang layak maka persentase minimal yang harus didapatkan yaitu sebesar 68,00\%. Sehingga media yang dikembangkan sudah dapat dimanfaatkan untuk alat belajar mengajar khusus pada materi motor bakar di kelas X TBSM.

\section{HASIL DAN PEMBAHASAN}

Hasil dari penelitian dan pengembangan ini adalah sebuah media pembelajaran yang menggunakan dua Software yaitu Solidworks 2014 dan Adobe Flash CS3 pada mata pelajaran Teknologi Dasar Otomotif, dengan materi Motor Bakar tingkat kelayakan dan tanggapan dari ahli materi, ahli media, dan tanggapan siswa melalui uji lapangan pada kelas $X$ TBSM1 di SMK Negeri 3 Singaraja, dalam kelompok kecil dan kelompok besar. Dalam pengembangan media pembelajaran yang efektif selalu diawali dengan pengidentifikasian tujuan, kebutuhan belajar, atau dalam beberapa hal masalahmasalah yang muncul dalam bentuk proses belajar mengajar.

Hasil dari perhitungan validasi ahli isi instrumen yang dilakukan oleh dua orang ahli isi instrumen yaitu: (1) Bapak Kadek Rihendra Dantes, S.T., M.T. dan (2) Bapak Alit Putra Mahardana, S.T., M.Pd. hasil validasi dari kedua ahli isi instrumen dan hasil perhitungannya sebagai berikut:

Tabel 03 Hasil Uji Validitas isi Instrumen

\begin{tabular}{|c|c|c|c|c|c|}
\hline \multirow{2}{*}{ No } & \multirow{2}{*}{ Komponen Penilaian } & \multicolumn{2}{|c|}{$\begin{array}{c}\text { Penguji } \\
1\end{array}$} & \multicolumn{2}{|c|}{$\begin{array}{c}\text { Penguji } \\
2\end{array}$} \\
\hline & & $\mathbf{R}$ & TR & $\mathbf{R}$ & TR \\
\hline \multirow[t]{2}{*}{1} & \multicolumn{5}{|c|}{ Kelayakan Instrumen Ahli Materi } \\
\hline & \multicolumn{5}{|c|}{ A. Penilaian isi Materi pada Media } \\
\hline 1 & $\begin{array}{l}\text { Kompetensi Dasar (KD) } \\
\text { pada media sudah sesuai } \\
\text { dengan KD silabus mata } \\
\text { pelajaran Teknologi } \\
\text { Dasar Otomotif }\end{array}$ & $\sqrt{ }$ & & $\sqrt{ }$ & \\
\hline 2 & $\begin{array}{l}\text { Materi pada media ini } \\
\text { sesuai } \begin{array}{r}\text { dengan } \\
\text { kompetensi dasar yang } \\
\text { telah ditentukan }\end{array} \\
\end{array}$ & $\sqrt{ }$ & & $\sqrt{ }$ & \\
\hline 3 & $\begin{array}{l}\text { Relevansi materi dengan } \\
\text { tujuan pembelajaran } \\
\text { pada media sudah sesuai }\end{array}$ & $\sqrt{ }$ & & $\sqrt{ }$ & \\
\hline 4 & $\begin{array}{l}\text { Isi materi pada media } \\
\text { sudah cukup lengkap }\end{array}$ & $\sqrt{ }$ & & $\sqrt{ }$ & \\
\hline 5 & $\begin{array}{l}\text { Video animasi pada } \\
\text { media mendukung materi } \\
\text { pembelajaran }\end{array}$ & $\sqrt{ }$ & & $\sqrt{ }$ & \\
\hline 6 & $\begin{array}{lr}\text { Adanya gambar bergerak } \\
\text { terkait dengan materi } \\
\text { yang } & \text { mampu } \\
\text { menghilangkan jenuh } \\
\text { siswa saat belajar }\end{array}$ & $\sqrt{ }$ & & $\sqrt{ }$ & \\
\hline \multirow[t]{2}{*}{7} & $\begin{array}{l}\text { Latihan soal pada media } \\
\text { sesuai dengan materi }\end{array}$ & $\sqrt{ }$ & & $\sqrt{ }$ & \\
\hline & \multicolumn{5}{|c|}{ B. Penilaian Sajian Materi pada Media } \\
\hline 8 & $\begin{array}{l}\text { Materi pada media } \\
\text { disajikan dengan bahasa } \\
\text { yang mudah dimengerti } \\
\text { untuk siswa }\end{array}$ & $\sqrt{ }$ & & $\sqrt{ }$ & \\
\hline 9 & 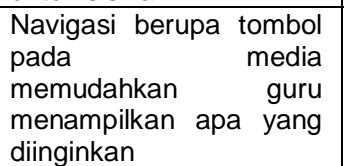 & $\sqrt{ }$ & & $\sqrt{ }$ & \\
\hline 10 & $\begin{array}{ll}\text { Audio pada } & \text { setiap } \\
\text { penjelasan isi } & \text { materi } \\
\text { sudah tepat }\end{array}$ & $\sqrt{ }$ & & $\sqrt{ }$ & \\
\hline 11 & $\begin{array}{l}\text { Penyajian materi pada } \\
\text { media ditampilkan secara } \\
\text { sistematis }\end{array}$ & $\sqrt{ }$ & & $\sqrt{ }$ & \\
\hline 12 & $\begin{array}{l}\text { Kedalaman materi yang } \\
\text { disajikan dalam media } \\
\text { sudah baik }\end{array}$ & $\sqrt{ }$ & & $\sqrt{ }$ & \\
\hline 13 & $\begin{array}{l}\text { Kejelasan Penyampaian } \\
\text { materi pada media }\end{array}$ & $\sqrt{ }$ & & $\sqrt{ }$ & \\
\hline 14 & $\begin{array}{l}\text { Tampilan pada media } \\
\text { membuat penjelasan } \\
\text { materi lebih menarik }\end{array}$ & $\sqrt{ }$ & & $\sqrt{ }$ & \\
\hline 15 & $\begin{array}{lrr}\text { Penempatan } & \text { gambar } \\
\text { ilustrasi dan } & \text { video } \\
\text { animasi pada media } \\
\text { sudah sesuai tempat }\end{array}$ & $\sqrt{ }$ & & $\sqrt{ }$ & \\
\hline \multirow[t]{2}{*}{ II } & \multicolumn{5}{|c|}{ Kelayakan Instrumen Ahli Media } \\
\hline & \multicolumn{5}{|l|}{ A. Huruf dan Warna } \\
\hline 1 & $\begin{array}{l}\text { Penggunaan jenis huruf } \\
\text { jelas untuk dibaca. }\end{array}$ & $\sqrt{ }$ & & $\sqrt{ }$ & \\
\hline 2 & Pemakaian warna & $\sqrt{ }$ & & $\sqrt{ }$ & \\
\hline 3 & $\begin{array}{l}\text { Ukuran huruf sudah } \\
\text { nyaman untuk dibaca }\end{array}$ & $\sqrt{ }$ & & $\sqrt{ }$ & \\
\hline & B. Kebahasaan dan Pen & & & & \\
\hline
\end{tabular}




\begin{tabular}{|c|c|c|c|c|c|}
\hline \multirow{2}{*}{ No } & \multirow{2}{*}{ Komponen Penilaian } & \multicolumn{2}{|c|}{$\begin{array}{c}\text { Penguji } \\
1\end{array}$} & \multicolumn{2}{|c|}{$\begin{array}{c}\text { Penguji } \\
2\end{array}$} \\
\hline & & $\mathbf{R}$ & TR & $\mathbf{R}$ & TR \\
\hline 4 & $\begin{array}{l}\text { Bahasa pada media } \\
\text { mudah dipahami }\end{array}$ & $\sqrt{ }$ & & $\sqrt{ }$ & \\
\hline 5 & $\begin{array}{l}\text { Penggunaan Bahasa } \\
\text { sudah sesuai EYD }\end{array}$ & $\sqrt{ }$ & & $\sqrt{ }$ & \\
\hline \multirow[t]{2}{*}{6} & $\begin{array}{l}\text { Format penulisan yang } \\
\text { terdapat pada media } \\
\text { sudah baik. }\end{array}$ & $\sqrt{ }$ & & $\sqrt{ }$ & \\
\hline & \multicolumn{5}{|c|}{ C. Desain, Tampilan, dan Audio } \\
\hline 7 & $\begin{array}{lrr}\text { Multimedia } & \text { seperti } \\
\text { gambar dan } & \text { video } \\
\text { animasi pada } & \text { media } \\
\text { tersedia lengkap } & \\
\end{array}$ & $\sqrt{ }$ & & $\sqrt{ }$ & \\
\hline 8 & $\begin{array}{l}\text { Gambar dan video } \\
\text { animasi membuat media } \\
\text { terlihat lebih menarik }\end{array}$ & $\sqrt{ }$ & & $\sqrt{ }$ & \\
\hline 9 & $\begin{array}{l}\text { Kualitas audio pada } \\
\text { media dapat didengar } \\
\text { dengan jelas }\end{array}$ & $\sqrt{ }$ & & $\sqrt{ }$ & \\
\hline 10 & $\begin{array}{l}\text { Sistematika penyajian } \\
\text { materi pada media sudah } \\
\text { bagus }\end{array}$ & $\sqrt{ }$ & & $\sqrt{ }$ & \\
\hline \multirow[t]{2}{*}{11} & $\begin{array}{l}\text { Desain icon tombol pada } \\
\text { media sudah bagus }\end{array}$ & $\sqrt{ }$ & & $\sqrt{ }$ & \\
\hline & \multicolumn{5}{|l|}{ D. Teknis Pengoprasian } \\
\hline 12 & $\begin{array}{l}\text { Petunjuk pengoperasian } \\
\text { mudah diikuti }\end{array}$ & $\sqrt{ }$ & & $\sqrt{ }$ & \\
\hline 13 & $\begin{array}{l}\text { Efektifitas navigasi pada } \\
\text { media }\end{array}$ & $\sqrt{ }$ & & $\sqrt{ }$ & \\
\hline 14 & $\begin{array}{l}\text { Media dapat dibuka } \\
\text { dengan mudah }\end{array}$ & $\sqrt{ }$ & & $\sqrt{ }$ & \\
\hline 15 & $\begin{array}{l}\text { Kemudahan } \\
\text { Pengoperasian media }\end{array}$ & $\sqrt{ }$ & & $\sqrt{ }$ & \\
\hline \multirow[t]{2}{*}{ III } & \multicolumn{5}{|c|}{ Kelayakan Instrumen Uji Lapangan } \\
\hline & \multicolumn{5}{|l|}{ A. Minat dalam KBM } \\
\hline 1 & $\begin{array}{l}\text { Media ini membuat saya } \\
\text { tertarik memperhatikan } \\
\text { penyampaian materi dari } \\
\text { guru }\end{array}$ & $\sqrt{ }$ & & $\sqrt{ }$ & \\
\hline 2 & $\begin{array}{l}\text { Adanya video animasi } \\
\text { pada media ini tidak } \\
\text { membuat saya mudah } \\
\text { bosan dalam KBM }\end{array}$ & $\sqrt{ }$ & & $\sqrt{ }$ & \\
\hline 3 & $\begin{array}{l}\text { Isi materi sederhana } \\
\text { sehingga saya mudah } \\
\text { memahami penjelasan } \\
\text { guru }\end{array}$ & $\sqrt{ }$ & & $\sqrt{ }$ & \\
\hline \multirow[t]{2}{*}{4} & $\begin{array}{l}\text { Saya merasa antusias } \\
\text { mengikuti KBM dengan } \\
\text { digunakannya media ini } \\
\text { oleh guru }\end{array}$ & $\sqrt{ }$ & & $\sqrt{ }$ & \\
\hline & \multicolumn{5}{|l|}{ B. Perhatian dalam KBM } \\
\hline 5 & $\begin{array}{l}\text { Saya menjadi fokus } \\
\text { mengikuti KBM karena } \\
\text { media ini }\end{array}$ & $\sqrt{ }$ & & $\sqrt{ }$ & \\
\hline 6 & $\begin{array}{lr}\text { Penyampaian } & \text { materi } \\
\text { dengan } & \text { media } \\
\text { pembelajaran } & \text { ini } \\
\text { membuat saya } & \text { tidak } \\
\text { mudah mengantuk } & \\
\end{array}$ & $\sqrt{ }$ & & $\sqrt{ }$ & \\
\hline 7 & $\begin{array}{l}\text { Materi yang ditampilkan } \\
\text { pada media mudah } \\
\text { dimengerti oleh saya }\end{array}$ & $\sqrt{ }$ & & $\sqrt{ }$ & \\
\hline
\end{tabular}

\begin{tabular}{|c|c|c|c|c|c|}
\hline \multirow{2}{*}{ No } & \multirow{2}{*}{ Komponen Penilaian } & \multicolumn{2}{|c|}{$\begin{array}{c}\text { Penguji } \\
1\end{array}$} & \multicolumn{2}{|c|}{$\begin{array}{c}\text { Penguji } \\
2\end{array}$} \\
\hline & & $\mathbf{R}$ & TR & $\mathbf{R}$ & TR \\
\hline 8 & $\begin{array}{lr}\text { Saya lebih } & \text { tertarik } \\
\text { mengikuti KBM jika guru } \\
\text { menyampaikan } & \text { materi } \\
\text { menggunakan } & \text { media } \\
\text { pembelajaran ini } & \\
\end{array}$ & $\sqrt{ }$ & & $\sqrt{ }$ & \\
\hline 9 & $\begin{array}{l}\text { Saya mendukung } \\
\text { penggunaan media ini } \\
\text { dalam penyampaian } \\
\text { materi Motor Bakar. }\end{array}$ & $\sqrt{ }$ & & $\sqrt{ }$ & \\
\hline 10 & $\begin{array}{lr}\text { Saya lebih jelas } \\
\text { mendengarkan suara } \\
\text { penjelasan materi dari } \\
\text { audio } \\
\text { pembelajaran ini media }\end{array}$ & $\sqrt{ }$ & & $\sqrt{ }$ & \\
\hline
\end{tabular}

\section{Partisipasi dalam KBM}

\begin{tabular}{|c|l|l|l|l|l|}
\hline 11 & $\begin{array}{l}\text { Dengan digunakannya } \\
\text { media ini oleh guru, saya } \\
\text { lebih aktif menjawab jika } \\
\text { ada pertanyaan terkait } \\
\text { materi yang disampaikan }\end{array}$ & $\sqrt{ }$ & & $\sqrt{ }$ & \\
\hline $12 \quad \begin{array}{l}\text { Saya menjadi aktif } \\
\text { bertanya karena materi } \\
\text { yang disampaikan } \\
\text { menggunakan media ini }\end{array}$ & $\sqrt{ }$ & & $\sqrt{ }$ & \\
\hline $\begin{array}{l}\text { Jumlah Masing-masing } \\
\text { Validitas Penguji }\end{array}$ & $\mathbf{4 2}$ & $\mathbf{0}$ & $\mathbf{4 2}$ & $\mathbf{0}$ \\
\hline Rata-rata Validitas dari dua \\
Penguji
\end{tabular}

Ket.

$\mathrm{R}$ = Relevan

TR = Tidak Relevan

Tabel 04 Perhitungan dengan tabel tabulasi silang (2x2) Gregory

\begin{tabular}{|c|c|c|c|}
\cline { 3 - 4 } \multicolumn{2}{c|}{} & \multicolumn{2}{c|}{ Penguji I } \\
\cline { 3 - 4 } \multicolumn{2}{c|}{} & $\begin{array}{c}\text { Tidak } \\
\text { Relevan }\end{array}$ & Relevan \\
\hline \multirow{3}{*}{$\begin{array}{c}\text { Penguji } \\
2\end{array}$} & Tidak & $($ A) & $($ B) \\
& Relevan & $(0)$ & $(0)$ \\
\cline { 2 - 4 } & Relevan & $($ C) & $($ D) \\
& (0) & $(42)$ \\
\hline
\end{tabular}

$$
\begin{aligned}
V i & =\frac{D}{A+B+C+D} \\
V i & =\frac{42}{0+0+0+42}
\end{aligned}
$$

$\boldsymbol{V} \boldsymbol{i}=\mathbf{1 . 0 0}$ satkan dan merujuk pada tabel kriteria validitas instrumen, maka disimpulkan bahwa isi instrumen memperoleh validitas konstruk 1,00 dengan kriteria derajat validitas sangat tinggi, sehingga instrumen ini dapat di sebar ke ahli materi, ahli media dan kelompok kecil serta kelompok besar

Hasil dari perhitungan validasi ahli materi yang dilakukan oleh dua orang ahli materi yaitu (1) Alfian Hariyadi, S.Pd. 
selaku guru pengampu mata pelajaran Teknologi Dasar Otomotif (TDO) materi motor bakar dan (2) Ketut Gunawan, S.T., M.T., selaku dosen yang memiliki kompetensi pada materi Motor Bakar, dimana berdasarkan persentase tersebut didapatkan hasil untuk isi materi yaitu sebesar $85,33 \%$ dengan kriteria sangat layak.

Tabel 03 Hasil Uji Ahli Materi

\begin{tabular}{|c|c|c|c|c|c|c|c|c|c|c|c|c|c|c|c|}
\hline \multirow[t]{2}{*}{ Nama Ahli } & \multicolumn{15}{|c|}{ Butir Soal } \\
\hline & 1 & 2 & \begin{tabular}{|l|}
3 \\
\end{tabular} & 4 & 5 & \begin{tabular}{|l|}
6 \\
\end{tabular} & 7 & \begin{tabular}{|l|}
8 \\
\end{tabular} & 9 & 10 & \begin{tabular}{|l|}
11 \\
\end{tabular} & \begin{tabular}{|l|}
12 \\
\end{tabular} & \begin{tabular}{|l|}
13 \\
\end{tabular} & 14 & \begin{tabular}{|l|l}
15 \\
\end{tabular} \\
\hline $\begin{array}{l}\text { Alfian } \\
\text { Hariyadi, } \\
\text { S.Pd., }\end{array}$ & 5 & 4 & 5 & 5 & 5 & 5 & 4 & 5 & 5 & 5 & 5 & 4 & 5 & 4 & 5 \\
\hline $\begin{array}{l}\text { Ketut } \\
\text { Gunawan, } \\
\text { S.T., M.T., }\end{array}$ & 4 & 4 & 4 & 3 & 4 & 4 & 4 & 4 & 4 & 3 & 4 & 4 & 4 & 4 & 3 \\
\hline $\begin{array}{c}\text { Rata-rata } \\
\text { Nilai } \\
\end{array}$ & 4,5 & 4 & 4,5 & 4 & 4,5 & 4,5 & 4 & 4,5 & 4,5 & 4 & 4,5 & 4 & 4,5 & 4 & 4 \\
\hline Total Nilai & \multicolumn{15}{|c|}{64} \\
\hline Persentase & \multicolumn{15}{|c|}{$85,33 \%$} \\
\hline
\end{tabular}

Hasil dari perhitungan validasi ahli media yang dilakukan oleh dua orang ahli media yaitu (1) Prof. Dr. I Made Candiasa M.I, Komp. Dan (2) Dr. I Gde Wawan Sudatha, S.Pd., S.T., M.Pd., Selaku ahli media, dimana berdasarkan persentase tersebut didapatkan hasil sebesar 90\% dengan kriteria sangat layak.

\begin{tabular}{|c|c|c|c|c|c|c|c|c|c|c|c|c|c|c|c|}
\hline \multirow[t]{2}{*}{ Nama Ahli } & \multicolumn{15}{|c|}{ Butir Soal } \\
\hline & 1 & 2 & \begin{tabular}{|l|}
3 \\
\end{tabular} & 4 & 5 & 6 & \begin{tabular}{|l|}
7 \\
\end{tabular} & \begin{tabular}{|l|}
8 \\
\end{tabular} & \begin{tabular}{|l|}
9 \\
\end{tabular} & 10 & 11 & 12 & 13 & 14 & 15 \\
\hline $\begin{array}{l}\text { Prof. Dr. I } \\
\text { Made } \\
\text { Candiasa } \\
\text { M.I, Komp. }\end{array}$ & 5 & 5 & 4 & 4 & 5 & 4 & 5 & 4 & 5 & 5 & 4 & 4 & 5 & 4 & 5 \\
\hline $\begin{array}{l}\text { Dr. I Gde } \\
\text { Wawan } \\
\text { Sudatha, } \\
\text { S.Pd., S.T., } \\
\text { M.Pd., }\end{array}$ & 5 & 4 & 5 & 5 & 4 & 4 & 4 & 4 & 4 & 4 & 4 & 4 & 5 & 5 & 5 \\
\hline $\begin{array}{c}\text { Rata-rata } \\
\text { Nilai }\end{array}$ & 5 & 4,5 & 4,5 & 4,5 & 4,5 & 4,5 & 4,5 & 4 & 4,5 & 4,5 & 4 & 4 & 5 & 4,5 & 5 \\
\hline Total Nilai & \multicolumn{15}{|c|}{67,5} \\
\hline Persentase & \multicolumn{15}{|c|}{$90 \%$} \\
\hline $\begin{array}{l}\text { diken } \\
\text { SMK } \\
\text { dilak } \\
\text { jumla } \\
\text { dima } \\
\text { didap } \\
\text { kriter }\end{array}$ & & S & $\mathrm{l}$ & d & jac & da & $\begin{array}{l}\text { ob } \\
\text { sis } \\
\text { raja } \\
\text { om } \\
\text { dig } \\
\text { p } \\
\text { oes }\end{array}$ & $\begin{array}{l}\text { a } \\
\text { wa } \\
\text { a, } \\
\text { po } \\
\text { jun } \\
\text { ers } \\
\text { sar }\end{array}$ & $\begin{array}{l} \\
\mathrm{ke} \\
\mathrm{dim} \\
\mathrm{k} \\
\mathrm{lak} \\
\text { sen }\end{array}$ & $\begin{array}{l}\text { ne } \\
\text { nas } \\
\text { ke }\end{array}$ & $\begin{array}{l}\text { dia } \\
\text { X } \\
\text { la t } \\
\text { cil } \\
10\end{array}$ & $\begin{array}{l}\text { dah } \\
\text { de }\end{array}$ & $\begin{array}{l}\text { iap } \\
\text { en }\end{array}$ & $\begin{array}{l}\text { ang } \\
\text { in } \\
\text { gar }\end{array}$ & \\
\hline
\end{tabular}

Tabel 05 Hasil Uji Kelompok Kecil

\begin{tabular}{|c|c|c|c|c|c|c|c|c|c|c|c|c|}
\hline \multirow{2}{*}{$\begin{array}{c}\text { Kode } \\
\text { Siswa }\end{array}$} & \multicolumn{10}{|c|}{ Butir Soal } \\
\cline { 2 - 15 } & $\mathbf{1}$ & $\mathbf{2}$ & $\mathbf{3}$ & $\mathbf{4}$ & $\mathbf{5}$ & $\mathbf{6}$ & $\mathbf{7}$ & $\mathbf{8}$ & $\mathbf{9}$ & $\mathbf{1 0}$ & $\mathbf{1 1}$ & $\mathbf{1 2}$ \\
\hline 1 & 4 & 4 & 5 & 4 & 4 & 4 & 5 & 4 & 5 & 4 & 4 & 4 \\
\hline 2 & 5 & 4 & 4 & 5 & 4 & 5 & 5 & 4 & 5 & 4 & 5 & 4 \\
\hline 3 & 4 & 5 & 4 & 5 & 4 & 5 & 4 & 5 & 4 & 5 & 5 & 4 \\
\hline 4 & 5 & 4 & 5 & 5 & 4 & 5 & 4 & 5 & 4 & 5 & 4 & 5 \\
\hline 5 & 4 & 4 & 4 & 4 & 3 & 4 & 4 & 4 & 4 & 4 & 4 & 4 \\
\hline 6 & 5 & 4 & 4 & 4 & 5 & 4 & 5 & 4 & 4 & 5 & 4 & 4 \\
\hline 7 & 4 & 4 & 4 & 4 & 4 & 4 & 4 & 4 & 4 & 4 & 4 & 4 \\
\hline 8 & 4 & $\mathbf{5}$ & 4 & $\mathbf{5}$ & 4 & $\mathbf{5}$ & $\mathbf{5}$ & $\mathbf{5}$ & 4 & $\mathbf{5}$ & 4 & $\mathbf{5}$ \\
\hline
\end{tabular}

Hasil uji coba media yang dikembangkan pada siswa kelas X TBSM1 SMK Negeri 3 Singaraja, dimana tahap ini dilakukan pada kelompok besar dengan jumlah siswa keseluruhan 31 siswa, dimana berdasarkan persentase tersebut didapatkan hasil sebesar $89,2 \%$ dengan kriteria sangat layak.

\section{Tabel 06 Hasil Uji Kelompok Besar}

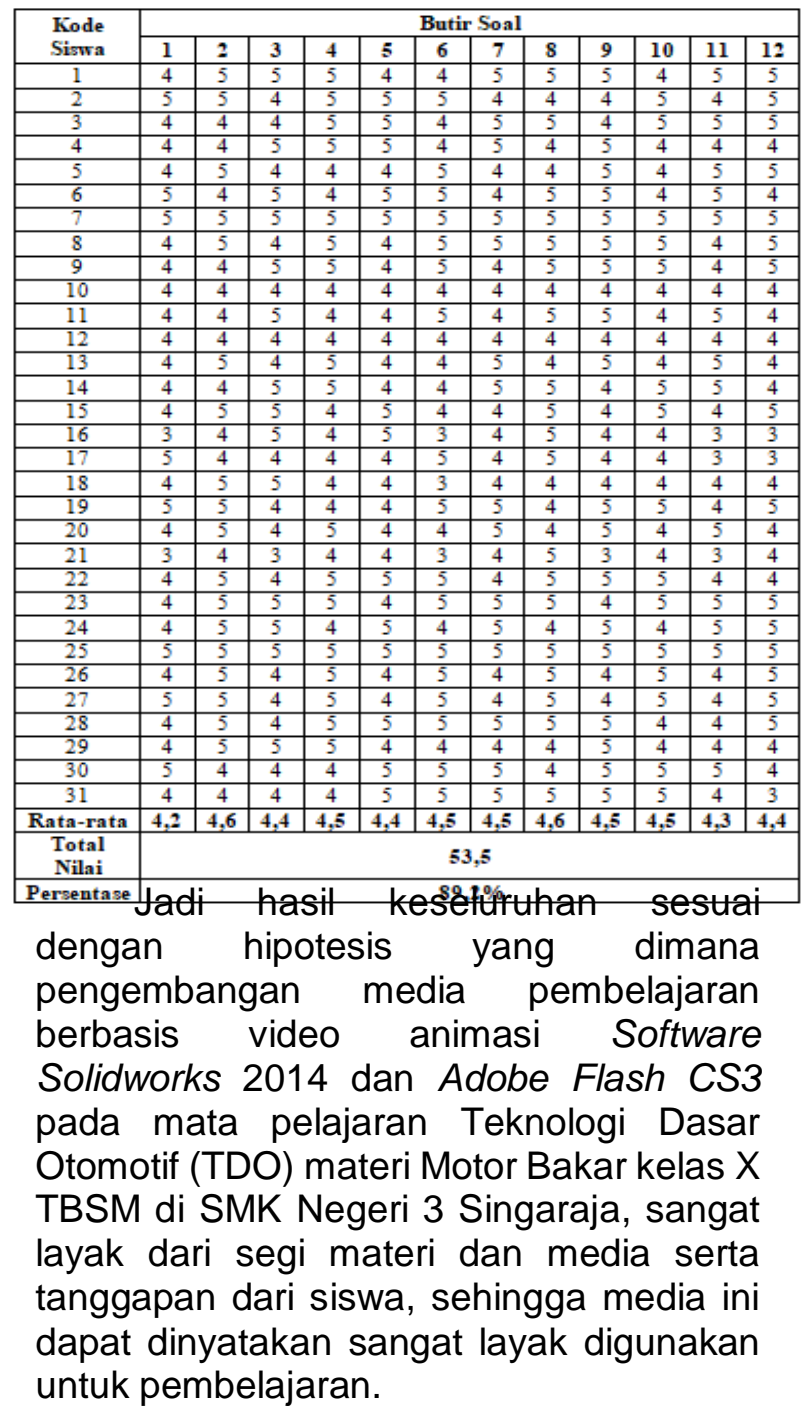


Adapun tampilan media final dapat dilihat pada gambar-gambar berikut ini:
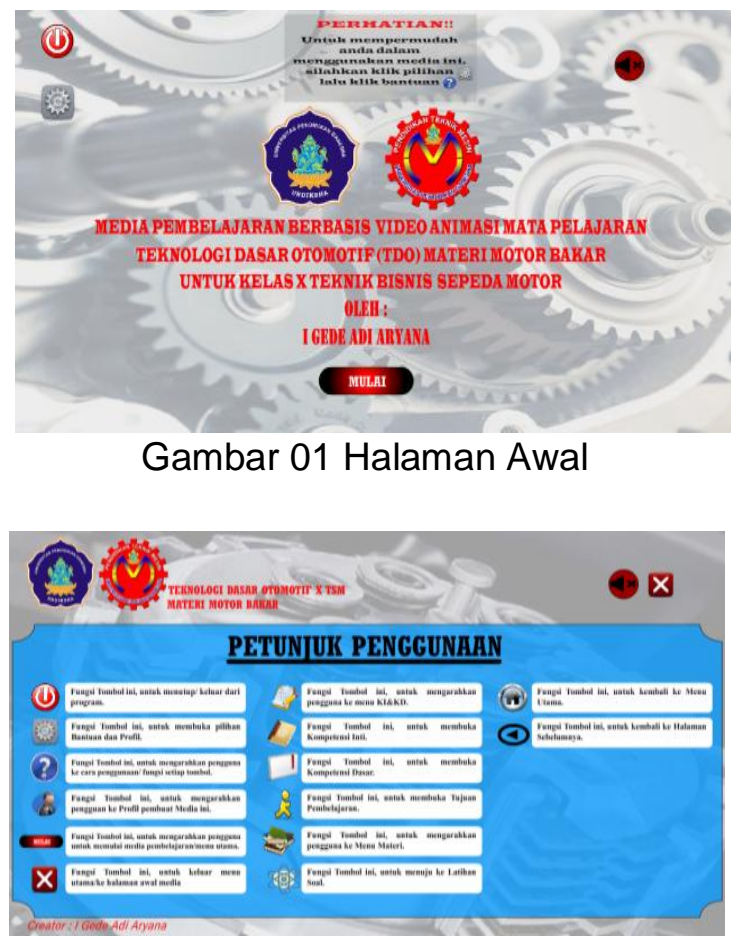

Gambar 02 Petunjuk penggunaan

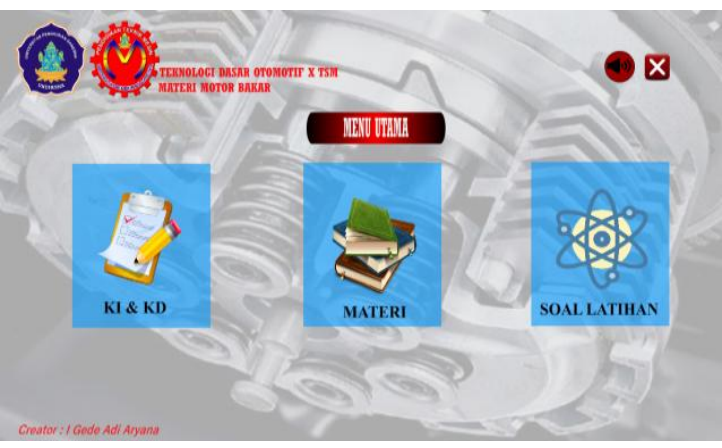

Gambar 03 Menu Utama

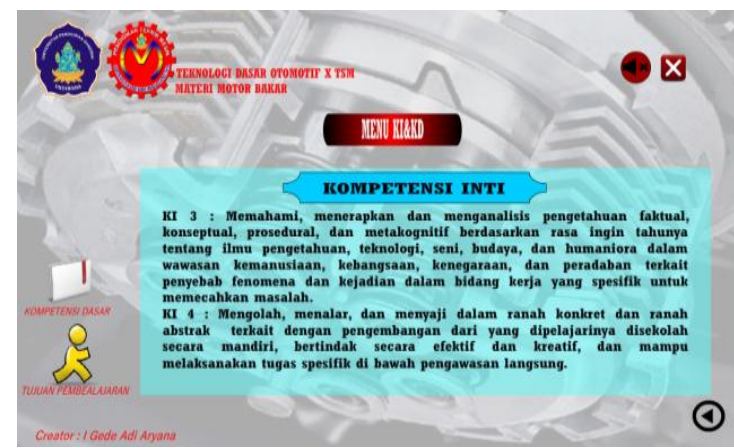

Gambar 04 Menu KI\&KD

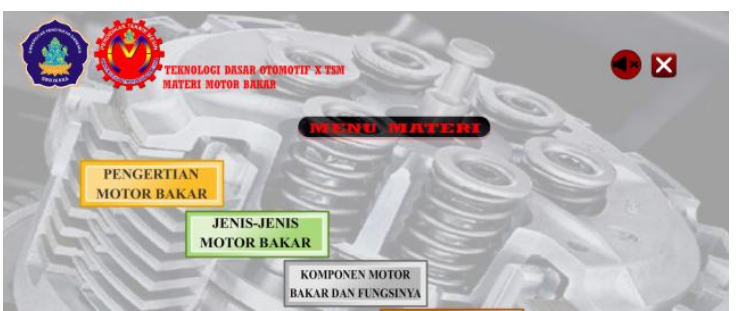

Gambar 05 Menu Materi

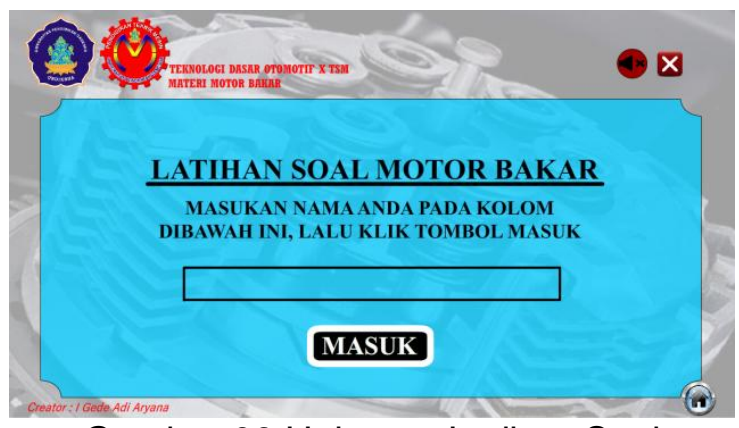

Gambar 06 Halaman Latihan Soal

\section{SIMPULAN DAN SARAN}

Kesimpulan dari penelitian dan pengembangan media pembelajaran berbasis video animasi Software Solidworks 2014 dan Adobe Flash CS3 pada mata pelajaran Teknologi Dasar Otomotif (TDO) materi motor bakar di SMK Negeri 3 Singaraja sebagai berikut:

1) Pada penelitian ini menggunakan model pengembangan 4-D (Four-D model). Yang terdiri dari empat tahap yaitu tahap pendefinisian (define), tahap perancangan (design), tahap pengembangan (development), dan penyebaran (deseminate). Namun, pada penelitian ini baru dilakukan 3 tahap saja yaitu tahap pendefinisian (Define), tahap perancangan (Design), tahap pengembangan (Develop). Dibuatkan media awal yang diujikan kepada dua ahli materi, dua ahli media, dan siswa kelas $X$ TBSM 1, dengan menggunakan kuesioner dan tingkatannya ada lima katagori yaitu nilai 5 ( sangat baik), 4 (baik), 3(cukup), 2 (kurang baik) dan 1 (tidak menarik). Terdapat komentar dan saran untuk segi materi, segi media, uji lapangan kelompok kecil, dan uji lapangan kelompok besar. Sehingga menghasilkan media yang sangat layak digunakan sebagai media pembelajaran. 
2) Hasil dari penelitia ini meliputi tingkat kelayakan materi $85,33 \%$. Untuk kelayakan media didapatkan 90\%. Kemudian setelah melakukan uji materi dan uji media yang dilakukan oleh ahli materi dan ahli media. Selanjutnya akan diujikan pada kelas $X$ TBSM1 yang dilakukan dua tahap. Tahap pertama pada kelompok kecil yang terdiri dari 10 siswa. Dan tahap kedua pada kelompok besar yang terdiri dari semua siswa kelas $X$ TBSM1. Dari hasil uji coba kelompok kecil didapatkan hasil dengan persentase sebesar $86,5 \%$, dan kelompok besar sebesar 89,2\%. Dari pemaparan kesimpulan tersebut maka media ini dapat dinyatakan sangat layak digunakan sebagai media pembelajaran dari segi materi maupun segi media, serta adanya tanggapan yang sangat layak dari siswa kelas X TBSM1 di SMK Negeri 3 Singaraja. terkait Saran yang dapat disampaikan pembelajaran berbasis video animasi Software Solidworks 2014 dan Adobe Flash CS3 yaitu sebagai berikut:

1) Bagi Guru Media ini dapat digunakan untuk mengajar pada mata pelajaran Teknologi Dasar Otomotif (TDO), materi motor bakar dengan dipadukan dengan metode pembelajaran yang sesuai sehingga proses belajar mengajar membuat perhatian siswa lebih fokus dan guru juga bisa mengubah ini terkait materi yang diajarkan. Guru juga dapat memberikan softcopy kepada siswa agar siswa bisa mempelajari materi motor bakar di rumahnya.

2) Bagi Siswa Media ini selain bisa digunakan di sekolah, softcopy media ini bisa diminta kepada guru agar bisa dipelajari di rumah oleh siswa sehingga pemahaman siswa terkait Materi Motor Bakar bisa lebih baik lagi dari sebelumnya dan termotivasi dalam belajar.

3) Bagi peneliti lain, media ini bisa dikembangkan lagi dari segi isinya atau materi baru yang ingin digunakan. Penelitian ini juga bisa digunakan sebagai referensi penelitian terkait pengembangan media atau bisa juga digunakan untuk diimplementasikan kepada siswa agar mengetahui ada atau tidaknya peningkatan hasil belajar pada siswa jika menggunakan media ini.

\section{DAFTAR PUSTAKA}

Arsyad, Azhar. 2013. Media Pembelajaran. Depok: PT RAJAGRAFINDO PERSADA

Borg \& Gall, 2003. Education Research. New York : Allyn and Bacon.

Gregory, R.J. (2000). Psychological Testing History, Principles and Applications. Boston: Allyn \& Bacon

Putra, Nusa. 2012. Metode Penelitian Kualitatif Pendidikan. (Jakarta: Rajawali Pers).

Salim, A. 2003. Pengertian Animasi dan Multimedia Pembelajaran. Jakarta : Elec media Komputindo.

Sarwanto. 2013. Belajar Cepat Desain Mesin 3D dengan Solidworks. Yogyakarta: Graha IImu

Sudaryono, dkk. 2013. Pengembangan Insrumen Penelitian Pendidikan. Yogyakarta: Graha IImu.

Sudjana, Nana dan Rivai, Ahmad. 2013. Media Pengajaran. Bandung: Sinar Baru Algensindo.

Sugiyono. 2012. Metode Penelitian Kualitatif, Kuantitatif dan $R \& D$. Bandung: Alfabeta.

Sugiyono. 2016. Statistika Untuk Penelitian. Bandung: Alfabeta

Suheri, Agus. 2006. Animasi Multimedia Pembelajaran. Jakarta : Elec media Komputindo.

Sukmadinata, Nana Syaodih. (2010). Metode Penelitian Pendidikan. Bandung: PT Remaja Rosdakarya.

Sutopo, Ariesto Hadi. 2003. Multimedia Interaktif dengan Flash. Yogyakarta: Graha IImu

Thiagarajan.1974. Four D Model-Model Pengembangan Perangkat Pembelajaran. Tersedia pada https://bustangbuhari.wordpress.com /2011/08/25/four-d-model-modelpengembangan-perangkat- 
JJTM, Vol. 7 No.3 Tahun:2019

pembelajaran-dari-thiagarajan -dkk/.

(Diakses tanggal 2 Desember 2018)

Purwanto, Ngalim. 2012. Evaluasi Hasil

Belajar. Yogyakarta: Pustaka Pelajar 